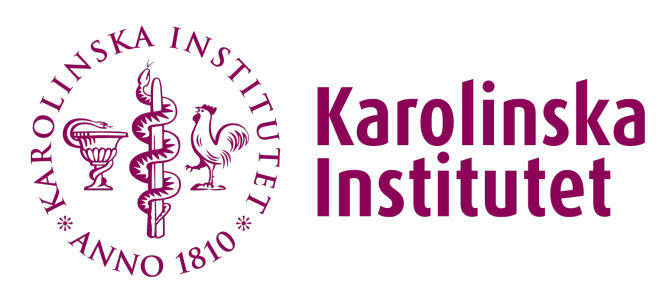

Karolinska Institutet

http://openarchive.ki.se

This is a Peer Reviewed Accepted version of the following article, accepted for publication in Acta Oncologica.

\title{
Tumour staging of oesophageal cancer in the Swedish Cancer Registry : a nationwide validation study
}

Brusselaers, Nele; Vall, Andreas; Mattsson, Fredrik; Lagergren, Jesper

Acta Oncol. 2015 Jun;54(6):903-8.

http://hdl.handle.net/10616/44568

If not otherwise stated by the Publisher's Terms and conditions, the manuscript is deposited under the terms of the Creative Commons Attribution-NonCommercial-NoDerivatives License (http://creativecommons.org/licenses/by-nc-nd/4.0/), which permits non-commercial re-use, distribution, and reproduction in any medium, provided the original work is properly cited, and is not altered, transformed, or built upon in any way. 


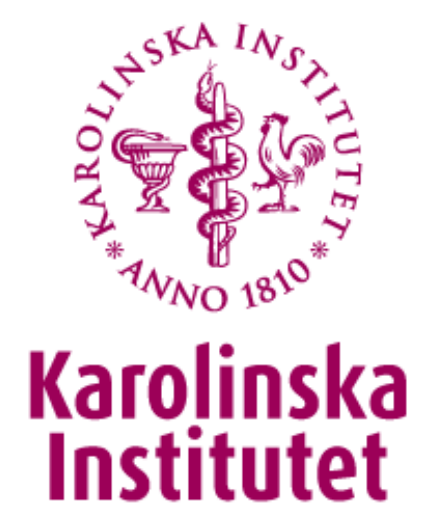

This is an author produced version of a paper published in Acta Oncologica. This paper has been peer-reviewed but does not include the final publisher proof-corrections or journal pagination.

\section{Tumour staging of oesophageal cancer in the Swedish Cancer Registry: a nationwide validation study.}

Brusselaers N, Vall A, Mattsson F, Lagergren, J esper.

Access to the published version may require subscription. Published with permission from: I nforma PIc. 


\section{Tumour staging of oesophageal cancer in the Swedish Cancer Registry: a nationwide validation study}

Authors: Nele BRUSSELAERS ${ }^{1}$, Andreas VALL ${ }^{1}$, Fredrik MATTSSON ${ }^{1}$, Jesper LAGERGREN ${ }^{1,2}$

Affiliations: ${ }^{1}$ Upper Gastrointestinal Surgery, Department of Molecular medicine and Surgery, Karolinska Institutet, Norra Stationsgatan 67, 17176 Stockholm, Sweden.

${ }^{2}$ Division of Cancer Studies, King's College London, United Kingdom.

Corresponding author: Dr. Nele Brusselaers, Upper Gastrointestinal Surgery, Department of Molecular medicine and Surgery, Norra Stationsgatan 67, $2^{\text {nd }}$ Floor, Karolinska Institutet, 17176 Stockholm, Sweden. Telephone: +46 (0)8 517709 42. E-mail: nele.brusselaers@ki.se

Acknowledgements: This study was funded by the Swedish Research Council (SIMSAM), and Swedish Cancer Society.

Word count: 2419 


\section{Abstract (word count: 250)}

Background: Tumour stage was introduced to the Swedish Cancer Registry in 2004, but this key variable for prognostic research has not yet been validated. We validated the tumour stage data in surgically treated oesophageal cancer patients.

Material and Methods: Completeness and accuracy of tumour stage according to the TNM system ("Tumour Node Metastasis") in the Cancer Registry were compared with a cohort study including comprehensive tumour stage data based on the pathological TNM of almost all patients operated for oesophageal cancer in 2006-2010 in Sweden.

Results: Of the 397 patients with pathological TNM data in the comparison cohort, the Cancer Registry reported an overall TNM stage in 390 patients (98.2\%), which was based on the pathological TNM of 104 patients (26.2\%), the clinical TNM of 183 patients (46.1\%), and the pathological or clinical TNM (undefined) of 110 patients (27.7\%). The completeness for the separate $\mathrm{T}, \mathrm{N}$, and $\mathrm{M}$ components was $89.4 \%, 90.9 \%$, and $85.1 \%$, respectively. The concordance with tumour stage was $98.2 \%$, while it was $51.1 \%, 70.5 \%$, and $80.4 \%$ for the separate $\mathrm{T}, \mathrm{N}$, and $\mathrm{M}$ components, respectively. While the concordance with tumour stage was high for all TNM assessment groups (98.1-98.4\%), the concordance of the $\mathrm{T}$ and $\mathrm{N}$ components was highest when using pathological TNM (82.7\% and $95.2 \%$, respectively), and the concordance of the $\mathrm{M}$ component was highest when using clinical TNM (88.5\%). 
Conclusion: Although the overall completeness of tumour stage is high, the recording of pathological TNM stage and individual components could be improved within the Swedish Cancer Registry.

Keywords: Validation; oesophageal cancer; classification; TNM system; stage. 


\section{Introduction}

Tumour stage is the most important prognostic factor for oesophageal cancer, a cancer characterised by a 5-year overall and postoperative survival of less than $15 \%$ and $35 \%$, respectively. ${ }^{1}$ Accurate cancer staging is crucial for predicting prognosis and deciding on treatment for these patients, and prognostic research heavily relies on accurate tumour stage data. The most commonly used staging system for oesophageal cancer is based on the TNM classification, which includes the local tumour growth (T), lymph node involvement $(\mathrm{N})$ and distant metastases $(\mathrm{M})$. TNM staging has been used since 1946 and has been updated regularly since, both by the Union International Contre le Cancer (UICC) and the American Joint Committee on Cancer (AJCC). ${ }^{2,3}$ TNM of oesophageal cancer is usually specified as clinical (cTNM) when it is based on findings from endoscopy and imaging prior to clinical decision-making, or pathological (pTNM) if it is based on a histological examination of a surgically resected specimen. Since pTNM is based on clinical information, supplemented or modified by the additional evidence acquired from surgery and from pathological examination, it is considered the most accurate way to report TNM. ${ }^{4}$ Information from the Swedish Cancer Registry is often used in cancer research, including prognostic studies, which highlights the need for complete and correct TNM registration. Tumour stage was added as a variable to the Swedish Cancer Registry in 2004, and this variable has, to the best of our knowledge, not been scientifically validated. Therefore, the objective of this study was to validate the completeness and accuracy of the TNM data available in the 
Swedish Cancer Registry in comparison with PTNM data collected in a comprehensive, nationwide Swedish cohort of oesophageal cancer patients who underwent tumour resection.

\section{Material and Methods}

\section{Design}

This was a validation study evaluating the completeness and accuracy of the TNM data, including the overall tumour stage, and T, N and $\mathrm{M}$ components, in the Swedish Cancer Register among patients who underwent surgical

resection for oesophageal cancer during the period $1^{\text {st }}$ January 2006 to $31^{\text {st }}$ December 2010. The comparison group ("gold standard") was a wellestablished nationwide Swedish cohort of oesophageal cancer patients, including high-quality data on PTNM, which has previously been used to investigate causes, surgical treatment and outcome in oesophageal cancer. ${ }^{5}$, ${ }^{6}$ The study was approved by the Regional Ethical Review Board in Stockholm, Sweden.

\section{Swedish Cancer Registry}

The Swedish Cancer Registry was founded in 1958 and has since captured the whole Swedish population. Registration by clinicians and pathologists is compulsory for all new cancer cases diagnosed clinically, morphologically or by laboratory tests or autopsy. Information about the patients as well as the type, site, histology and date of the cancer diagnosis is recorded. The overall completeness of cancer diagnoses in general is very high, ${ }^{7}$ and it is $98.3 \%$ 
complete for oesophageal cancer. ${ }^{8}$ TNM-staging was introduced in 2004, but we decided to start this validation study in 2006 , since incomplete and suboptimal reporting of TNM in the Cancer Registry was expected during the initial period. The $6^{\text {th }}$ edition of the TNM classification of the UICC was used to define TNM in the Cancer Registry (and in the comparison cohort). ${ }^{4}$ The doctors were required to fill in the information of every patient diagnosed with cancer, including text boxes for $\mathrm{T}, \mathrm{N}$ and $\mathrm{M}$, as well as tick boxes for whether the basis of the evaluation was clinical (cTNM) or pathological (pTNM). Whenever possible, reporting of pTNM was preferred over cTNM in the Cancer Registry, yet only one of both could be reported. The timing of the TNM staging was not collected in the Cancer Registry. The overall tumour stage was based on the summary of the reported T, N and M components and reproduced by the Cancer Registry. The board of health and welfare (Socialstyrelsen) recommends that these data should be reported as soon as the diagnosis is established and the required information is available, by the physician responsible for the clinical diagnosis of newly discovered tumours or tumour-like conditions. These data should then be sent to one of the six regional cancer centres in Sweden, where they are coded and registered, and then send to the National Board of Health Register and Welfare to be implemented in the Cancer Registry.

\section{Comparison cohort}

Our population-based surgery cohort study that was used as the comparison ("gold standard") included $97 \%$ of all patients who underwent curatively 
intended surgery for oesophageal cancer in Sweden during $1^{\text {st }}$ January 1987 to $31^{\text {st }}$ December 2010. Since the dataset of this comparison cohort included data from the year 2010, this was the final year of the present study. The comparison cohort is described in more detail elsewhere. ${ }^{5,9}$ In brief, its members were identified by linking data from the Swedish Cancer Registry and Swedish Patient Registry. The personal identity numbers, a 10-digit unique personal identifier of each person residing in Sweden, enabled registry linkages and retrieval of surgery and histopathology records from all hospitals involved in patients with oesophageal cancer in Sweden. All departments of pathology in Sweden were asked to send a copy of the histopathological record to the study secretariat for every patient in the study cohort. ${ }^{5}$ Tumour stage, location, and histological type were manually reviewed by one investigator and two investigators checked a random sample of this classification and found it to be highly accurate. ${ }^{5}$ Only patients with complete pTNM staging information were included in the comparison cohort. PTNM information was based on the histology reports and medical charts and defined by the $6^{\text {th }}$ edition of the TNM classification of the UICC. ${ }^{4}$ Data were collected on the overall tumour stage as well as the separate $T, N$ and $\mathrm{M}$ components.

\section{Statistical analysis}

Patients were classified into three TNM groups depending on whether the basis of the TNM was pathological (pTNM), clinical (cTNM), or unspecified (pTNM or cTNM). Patient-, tumour-, and treatment characteristics were 
compared, i.e. sex (male or female), age at diagnosis (three equally sized groups), tumour histology (adenocarcinoma or squamous cell carcinoma), calendar year of surgery (per year), hospital volume of oesophagectomies (three equally sized groups) and hospital type (university or non-university). For each group, the TNM classification as reported in the Cancer Registry was assessed for completeness and accuracy of the overall stage and each $\mathrm{T}, \mathrm{N}$ and $\mathrm{M}$ component. Stage was categorised into 4 groups (0-I, II, III, or IV), the T component into four groups (T0-1, T2, T3 or T4), the $\mathrm{N}$ component into two groups ( $\mathrm{N} 0$ or $\mathrm{N} 1$ ), and the $\mathrm{M}$ component into two groups (M0 or M1), all according to the $6^{\text {th }}$ edition of the TNM classification of the UICC. ${ }^{4}$ The categorisation of overall tumour stage used for our analyses is presented in Figure 1. Accuracy was expressed as concordance or the proportion of all scores that were identical in both data sources. The Cohen's Kappa statistic was used to evaluate the concordance between variables from the two cohorts, with a Kappa of 1 indicating complete concordance. ${ }^{10}$ All analyses were performed using the statistical software STATA (Stata Corp v13.0).

\section{Results}

\section{Patients}

Among 410 patients who underwent oesophagectomy for oesophageal cancer between 2006 and 2010 in Sweden, 13 were excluded because of incomplete TNM data in the comparison cohort, leaving 397 patients for final analysis. 


\section{Basis of the tumour stage assessment in the Cancer Registry}

Although the records of all study patients indicated that the cancer diagnosis in the Cancer Registry was based on "biopsy or operation with histopathological investigation", pTNM was reported for only 104 patients (26.2\%), while cTNM was reported for 183 patients (46.1\%). For the remaining 110 patients (27.7\%) it was not specified if any TNM information was based on clinical or pathological examination (Figure 2). As seen in Table 1, pTNM was reported more frequently in men, non-university hospitals and low-volume hospitals compared to their counterparts. The basis of tumour stage data was not specified in $84.6 \%$ of the patients in 2006, after which this proportion declined substantially. During the years 2008-2010, cTNM was reported approximately twice as frequently as pTNM. Patient age did not appear to influence the reported basis of tumour stage (Table 1).

\section{Completeness of tumour stage and $T, N$, and $M$ components in the}

\section{Cancer Registry}

For 395 out of 397 patients (99.5\%) at least some information was reported on tumour stage or one or more of the $\mathrm{T}, \mathrm{N}$ or $\mathrm{M}$ components in the Cancer Registry. The overall completeness of tumour stage and the $\mathrm{T}, \mathrm{N}$, and $\mathrm{M}$ components in the Cancer Registry was $98.2 \%, 89.4 \%, 90.9 \%$, and $85.1 \%$, respectively. The completeness is presented in Table 2 for all three TNM groups (pTNM, cTNM, and unspecified basis for TNM). The completeness of 
tumour stage was similar in all three types of TNM assessments (range 98.1-98.4\%)(Table 2). Most cases where T, N and M components were missing were patients in whom TNM was not specified. The completeness was higher for the PTNM data than the cTNM data for the T component (97.1\% and $92.3 \%$, respectively) and the $\mathrm{N}$ component (99.0\% and $95.6 \%$, respectively), while the $M$ component was less complete in the PTNM group compared to the cTNM group ( $85.6 \%$ and $95.1 \%$, respectively).

\section{Accuracy of tumour stage and $T, N$, and $M$ components in the Cancer}

\section{Registry}

The overall reporting concordance and Kappa statistics are presented in Table 2. The overall concordance between the Cancer Registry and the comparison cohort for tumour stage and $\mathrm{T}, \mathrm{N}$, and $\mathrm{M}$ components was 98.2\% (kappa 0.97), 51.1\% (kappa 0.34), 70.5\% (kappa 0.46), and 80.4\% (kappa 0.12 ), respectively. For all three types of TNM assessments, there was high concordance for stage (range 98.1-98.4\%, kappa 0.97-0.98), meaning that if tumour stage was reported, it was virtually identical to the tumour stage reported in the comparison cohort. The concordance for the T and $\mathrm{N}$ components was highest in the pTNM group, with $82.7 \%$ (kappa 0.76) for the T component and $95.2 \%$ (kappa 0.90 ) for the $\mathrm{N}$ component, while the concordance for the M component was highest in the cTNM group (88.5\%; kappa 0.18)(Table 2). 


\section{Discussion}

This validation study of tumour stage recorded in the Swedish Cancer Registry among patients operated for oesophageal cancer found a low reporting of pTNM, but when adding cTNM and unspecified basis for TNM the overall tumour stage was almost complete and highly accurate. The reporting of the separate TNM components was suboptimal, especially for the $\mathrm{T}$ and $\mathrm{N}$ components when the PTNM was not available.

A main strength of this study is the virtually complete assessment of eligible patients, which counteracts selection bias. Other advantages include the restriction to patients who underwent surgery, and therefore pathological examinations of the resected specimens were performed, as well as the accurate data of pathological tumour stage in the comparison cohort. A limitation is the lack of tumour stage data after the year 2010. A newer version $\left(7^{\text {th }}\right)$ of the TNM classification has been introduced, ${ }^{11}$ but the $6^{\text {th }}$ edition is currently still in use for reporting the TNM in the Swedish Cancer Registry. ${ }^{11}$ Another limitation is that we grouped some of the variables to obtain sufficiently large categories, including grouping of the tumour stage and T component into 4 groups rather than more specific categories. Finally, we did not have data on CTNM in the comparison cohort, which means that we could not validate this variable in any detail.

Although other validation studies have been performed to assess the quality of the Swedish Cancer Registry, ${ }^{12,13}$ this is to the best of our knowledge, the 
first validation study of the TNM staging in specific . It is unclear why PTNM is underreported, although it is requested from the Cancer Registry, and we cannot assess if differences in quality of TNM registration exist between the six regional cancer centres, or different hospitals. Possible explanations for the incomplete reporting of both pTNM and cTNM and the suboptimal reporting of the $\mathrm{T}, \mathrm{N}$, and $\mathrm{M}$ components in the Cancer Registry are that it is unclear who among the clinicians within the multidisciplinary team (oncologist, surgeon or pathologist) should report this data to the Cancer Registry, leaving a risk of non-reporting or that the quality of the reporting is decreased. It is also unclear what could happen if two different clinicians send it this registration form for the same patient and same cancer episode, when it contains slightly different information (e.g. cTNM and the other pTNM) since every cancer episode can only be registered once in the Cancer Registry. Another explanation for the low accuracy could be uncertainty of the timing of the reporting of TNM components, e.g. before or after neo-adjuvant therapy (which may have reduced the tumour size) or surgery (which allows histopathological examination and therefore more accurate staging). Unfortunately, the time point is not required to be reported when the information is submitted to the Cancer Registry. Although pTNM is the recommended TNM to report whenever available (which it is in all patients included in the present study), TNM was unclear or based on cTNM in the majority of patients, although it was stated that the diagnosis for all included patients was based on "biopsy or operation with histopathological investigation". Therefore, it may also be that the source of TNM is reported 
incorrectly as CTNM in some cases since the pathology data should have been available at that time. Unfortunately, distinguishing between biopsy and full histopathological investigation of the resected oesophagus was not possible because these data were not provided.

The main implications of these results are that PTNM is underreported, although it is requested by the Cancer Registry. However, the overall tumour stage is reliable for patients operated for oesophageal cancer, even when based on the cTNM or when it is unclear how the TNM is determined. In many cases, separate $\mathrm{T}, \mathrm{N}$ and $\mathrm{M}$ components appeared to be unreliable. The generalisability of these finding to other types of cancer are uncertain, but it is reasonable to assume that the problems encountered in the present study population would also exist for other tumours. However, the results might not be generalisable to non-operated patients, since the pTNM is not available.

To conclude, this nationwide Swedish validation study showed that the overall pTNM stage is incompletely reported, although this is compensated by a better reporting of cTNM staging and staging based on unspecified assessment. The $\mathrm{T}, \mathrm{N}$ and $\mathrm{M}$ components are suboptimally reported. It is important to improve the assessment of tumour stage in the Swedish Cancer Registry, including making it clear by whom and when the reporting is supposed to be done, and highlighting the need to report both the CTNM and pTNM in operated cancer patients. 


\section{References}

[1] Lagergren J, Lagergren P. Oesophageal cancer. BMJ. 2010;341:c6280.

[2] Denoix P. Enquete permanente dans les centres anticancereux. Bulletin Institut national d'hygiene (France). 1946 Jan-Mar;1:12-7.

[3] Greene FL, Sobin LH. The TNM system: our language for cancer care. J Surg Oncol. 2002 Jul;80(3):119-20.

[4] Sobin L, Wittekind C. International Union Against Cancer (UICC)- 6th edition: Classification of malignant tumours. 6th ed2002.

[5] Rouvelas I, Zeng W, Lindblad M, Viklund P, Ye W, Lagergren J. Survival after surgery for oesophageal cancer: a population-based study. Lancet Oncol. 2005 Nov;6(11):864-70.

[6] Derogar M, Sadr-Azodi O, Johar A, Lagergren P, Lagergren J. Hospital and surgeon volume in relation to survival after esophageal cancer surgery in a population-based study. J Clin Oncol. 2013 Feb 10;31(5):551-7.

[7] Barlow L, Westergren K, Holmberg L, Talback M. The completeness of the Swedish Cancer Register: a sample survey for year 1998. Acta Oncol. 2009;48(1):27-33.

[8] Lindblad M, Ye W, Lindgren A, Lagergren J. Disparities in the classification of esophageal and cardia adenocarcinomas and their influence on reported incidence rates. Ann Surg. 2006 Apr;243(4):479-85.

[9] Derogar M, Sadr-Azodi O, Johar A, Lagergren P, Lagergren J. Hospital and surgeon volume in relation to survival after esophageal cancer surgery in a population-based study. J Clin Oncol. 2013 Feb 10;31(5):551-7. 
[10] Cohen J. A coefficient of agreement for nominal scales. Educational and Psychological Measurement 1960;20:37-46.

[11] Talsma K, van Hagen P, Grotenhuis BA, Steyerberg EW, Tilanus HW, van Lanschot JJ, et al. Comparison of the 6th and 7th Editions of the UICCAJCC TNM Classification for Esophageal Cancer. Ann Surg Oncol. 2012 Jul;19(7):2142-8.

[12] Jorgren F, Johansson R, Damber L, Lindmark G. Validity of the Swedish Rectal Cancer Registry for patients treated with major abdominal surgery between 1995 and 1997. Acta Oncol. 2013 Nov;52(8):1707-14.

[13] Sandblom G, Dufmats M, Olsson M, Varenhorst E. Validity of a population-based cancer register in Sweden--an assessment of data reproducibility in the South-East Region Prostate Cancer Register. Scand J Urol Nephrol. 2003;37(2):112-9. 
Table 1: Descriptive characteristics of the cohort of patients operated for oesophageal cancer in Sweden in in 2006-2010.

\begin{tabular}{|c|c|c|c|c|}
\hline & $\begin{array}{c}\text { All } \\
\text { patients } \\
\text { Number } \\
(\%)\end{array}$ & $\begin{array}{c}\text { pTNM }^{*} \\
\text { Number } \\
(\%)\end{array}$ & $\begin{array}{c}\text { cTNM* }^{*} \\
\text { Number } \\
(\%)\end{array}$ & $\begin{array}{c}\text { TNM not } \\
\text { specified* } \\
\text { Number (\%) }\end{array}$ \\
\hline Total & $397(100.0)$ & $104(26.2)$ & $183(46.1)$ & $110(27.7)$ \\
\hline \multicolumn{5}{|l|}{ Sex } \\
\hline Men & $312(100)$ & $86(27.6)$ & $136(43.6)$ & $90(28.9)$ \\
\hline Women & $85(100)$ & $18(21.2)$ & $47(55.3)$ & $20(23.5)$ \\
\hline \multicolumn{5}{|l|}{ Age (years) } \\
\hline$<61$ & $138(100)$ & $39(28.3)$ & $59(42.8)$ & $40(29.0)$ \\
\hline $61-67$ & $128(100)$ & $34(26.6)$ & $62(48.4)$ & $32(25.0)$ \\
\hline$>67$ & $131(100)$ & $31(23.7)$ & $62(47.3)$ & $38(29.0)$ \\
\hline \multicolumn{5}{|l|}{ Year of resection } \\
\hline 2006 & $78(100)$ & $5(6.4)$ & $7(9.0)$ & $66(84.6)$ \\
\hline 2007 & $75(100)$ & $21(28.0)$ & $27(36.0)$ & $27(36.0)$ \\
\hline 2008 & $57(100)$ & $19(33.3)$ & $34(59.7)$ & $4(7.0)$ \\
\hline 2009 & $100(100)$ & $33(33.0)$ & $63(63.0)$ & $4(4.0)$ \\
\hline 2010 & $87(100)$ & $26(29.9)$ & $52(59.8)$ & $9(10.3)$ \\
\hline \multicolumn{5}{|l|}{ Histological tumour } \\
\hline Squamous cell carcinoma & $163(100)$ & $40(24.5)$ & $74(45.4)$ & $49(30.1)$ \\
\hline Adenocarcinoma & $212(100)$ & $52(24.5)$ & $105(49.5)$ & $55(25.9)$ \\
\hline Other & $22(100)$ & $12(54.6)$ & $4(18.2)$ & $6(27.3)$ \\
\hline \multicolumn{5}{|l|}{ Hospital type } \\
\hline University & $240(100)$ & $50(20.8)$ & $119(49.6)$ & $71(29.6)$ \\
\hline Non-university & $157(100)$ & $54(34.4)$ & $64(40.8)$ & $39(24.8)$ \\
\hline \multicolumn{5}{|l|}{$\begin{array}{l}\text { Hospital volume } \\
\text { (average per year) }\end{array}$} \\
\hline 1-8 oesophagectomies & $102(100)$ & $33(32.4)$ & $42(41.2)$ & $27(26.5)$ \\
\hline 9-16 oesophagectomies & $157(100)$ & $41(26.1)$ & $75(47.8)$ & $41(26.1)$ \\
\hline 16-21 oesophagectomies & $138(100)$ & $30(21.7)$ & $66(47.8)$ & $42(30.4)$ \\
\hline
\end{tabular}

Legend: pTNM, pathology based TNM staging; cTNM, clinically based TNM staging. *As reported in the Cancer Registry. 
Table 2: Completeness and concordance of the tumour stage and TNM components between the Swedish Cancer Registry and a comparison clinical cohort of patients receiving resection for oesophageal cancer in 2006-2010, presented per TNM source specified in the Cancer Registry.

\begin{tabular}{|c|c|c|c|c|c|c|}
\hline pTNM* $(N=104)$ & $\begin{array}{c}\text { Completeness, } \\
\text { Number (\%) }\end{array}$ & $\begin{array}{c}\text { Concordance, } \\
\%\end{array}$ & $\begin{array}{c}\text { Expected } \\
\text { concordance, } \\
\%\end{array}$ & Kappa & SE & $\mathbf{p}$ \\
\hline$T$ & $101(97.1)$ & 82.7 & 28.6 & 0.76 & 0.06 & $<0.001$ \\
\hline$N$ & 103 (99.0) & 95.2 & 49.9 & 0.90 & 0.10 & $<0.001$ \\
\hline$M$ & $89(85.6)$ & 81.7 & 77.1 & 0.20 & 0.05 & $<0.001$ \\
\hline Stage & $102(98.1)$ & 98.1 & 33.9 & 0.97 & 0.06 & $<0.001$ \\
\hline
\end{tabular}

\begin{tabular}{|c|c|c|c|c|c|c|}
\hline cTNM* $(\mathrm{N}=183)$ & $\begin{array}{c}\text { Completeness, } \\
\text { Number (\%) }\end{array}$ & $\begin{array}{c}\text { Concordance, } \\
\%\end{array}$ & $\begin{array}{c}\text { Expected } \\
\text { concordance, } \\
\%\end{array}$ & Kappa & SE & $\mathbf{p}$ \\
\hline$T$ & $169(92.3)$ & 31.7 & 26.3 & 0.07 & 0.04 & 0.029 \\
\hline$N$ & $175(95.6)$ & 59.6 & 48.4 & 0.21 & 0.07 & 0.001 \\
\hline$M$ & $174(95.1)$ & 88.5 & 86.0 & 0.18 & 0.05 & $<0.001$ \\
\hline Stage & $180(98.4)$ & 98.4 & 29.3 & 0.98 & 0.05 & $<0.001$ \\
\hline $\begin{array}{l}\text { TNM* not } \\
\text { specified } \\
(\mathrm{N}=110)\end{array}$ & $\begin{array}{c}\text { Completeness, } \\
\text { Number (\%) }\end{array}$ & $\begin{array}{c}\text { Concordance, } \\
\%\end{array}$ & $\begin{array}{c}\text { Expected } \\
\text { concordance, } \\
\%\end{array}$ & Карра & SE & $\mathbf{p}$ \\
\hline$T$ & $85(77.3)$ & 53.6 & 22.4 & 0.40 & 0.05 & $<0.001$ \\
\hline$N$ & $83(75.5)$ & 65.5 & 37.7 & 0.45 & 0.07 & $<0.001$ \\
\hline$M$ & $75(68.2)$ & 65.5 & 64.3 & 0.03 & 0.03 & 0.110 \\
\hline Stage & $108(98.2)$ & 98.2 & 29.8 & 0.97 & 0.06 & $<0.001$ \\
\hline
\end{tabular}

\begin{tabular}{lllllll}
\hline $\begin{array}{l}\text { All TNM* } \\
\text { assessments } \\
\text { (N=397) }\end{array}$ & $\begin{array}{l}\text { Completeness, } \\
\text { Number (\%) }\end{array}$ & $\begin{array}{l}\text { Concordance, } \\
\%\end{array}$ & $\begin{array}{l}\text { Expected } \\
\text { concordance, } \\
\%\end{array}$ & Kappa & SE & p \\
\hline $\boldsymbol{T}$ & $355(89.4)$ & 51.1 & 26.1 & 0.34 & 0.03 & $<0.001$ \\
$\mathbf{N}$ & $361(90.9)$ & 70.5 & 45.8 & 0.46 & 0.04 & $<0.001$ \\
$\boldsymbol{M}$ & $338(85.1)$ & 80.4 & 77.7 & 0.12 & 0.02 & $<0.001$ \\
Stage & $390(98.2)$ & 98.2 & 29.8 & 0.97 & 0.03 & $<0.001$ \\
\hline Legend: pTNM, pathology based TNM staging; CTNM, clinically based TNM \\
staging; SE, standard error. * T was categorised in 4 groups (T0-1, T2, T3 or \\
T4), N in 2 groups (N0 or N1), M in 2 groups (M0 or M1) and tumour stage in \\
4 groups (0-1, II, III, or IV).
\end{tabular}


Figure 1: The TNM classification for oesophageal cancer, adapted from the Union International Contre le Cancer (UICC) $6^{\text {th }}$ edition.

\begin{tabular}{|ll|}
\hline Stage 0-I & $\mathrm{T}_{0} \mathrm{~N}_{\text {any }} \mathrm{M}_{0}$ or $\mathrm{T}_{1} \mathrm{~N}_{0} \mathrm{M}_{0}$ \\
Stage II & $\mathrm{T}_{2,3} \mathrm{~N}_{0} \mathrm{M}_{0}$ or $\mathrm{T}_{1,2} \mathrm{~N}_{1} \mathrm{M}_{0}$ \\
Stage III & $\mathrm{T}_{3} \mathrm{~N}_{1} \mathrm{M}_{0}$ or $\mathrm{T}_{4} \mathrm{~N}_{\text {any }} \mathrm{M}_{0}$ \\
Stage IV & $\mathrm{T}_{\text {any }} \mathrm{N}_{\text {any }} \mathrm{M}_{1}$ \\
\hline
\end{tabular}


Figure 2: Flowchart describing the selection of the validation cohort of patients, operated for oesophageal cancer in Sweden.

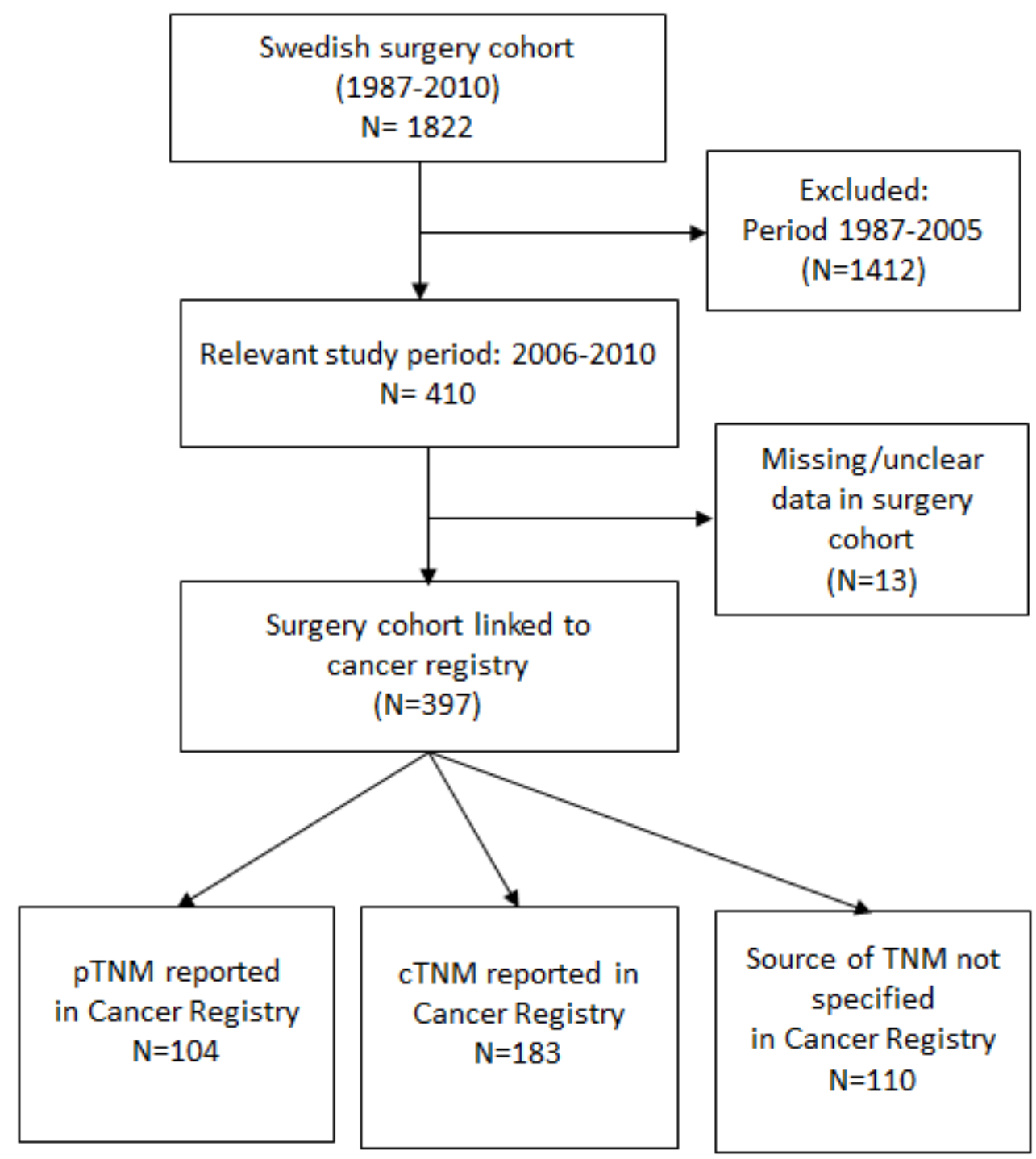

Legend: pTNM, pathology based TNM staging; cTNM, clinically based TNM staging. 